\title{
Insights on Exogenous Tryptophan-mediated Allosteric communication and Helical Transition of TRP protein for Transcription Regulation
}

\author{
Richard Mariadasse, Sanjay Kumar Choubey and Jeyaraman Jeyakanthan* \\ Structural Biology and Bio-Computing Lab, Department of Bioinformatics, Science Block, \\ Alagappa University, Karaikudi-630 004, Tamil Nadu, India
}

*Corresponding author:

\author{
Dr. J. Jeyakanthan \\ Professor and Head \\ Department of Bioinformatics \\ Alagappa University, \\ Karaikudi-6100004. \\ Email: jjkanthan@gmail.com
}




\section{Supporting Information}

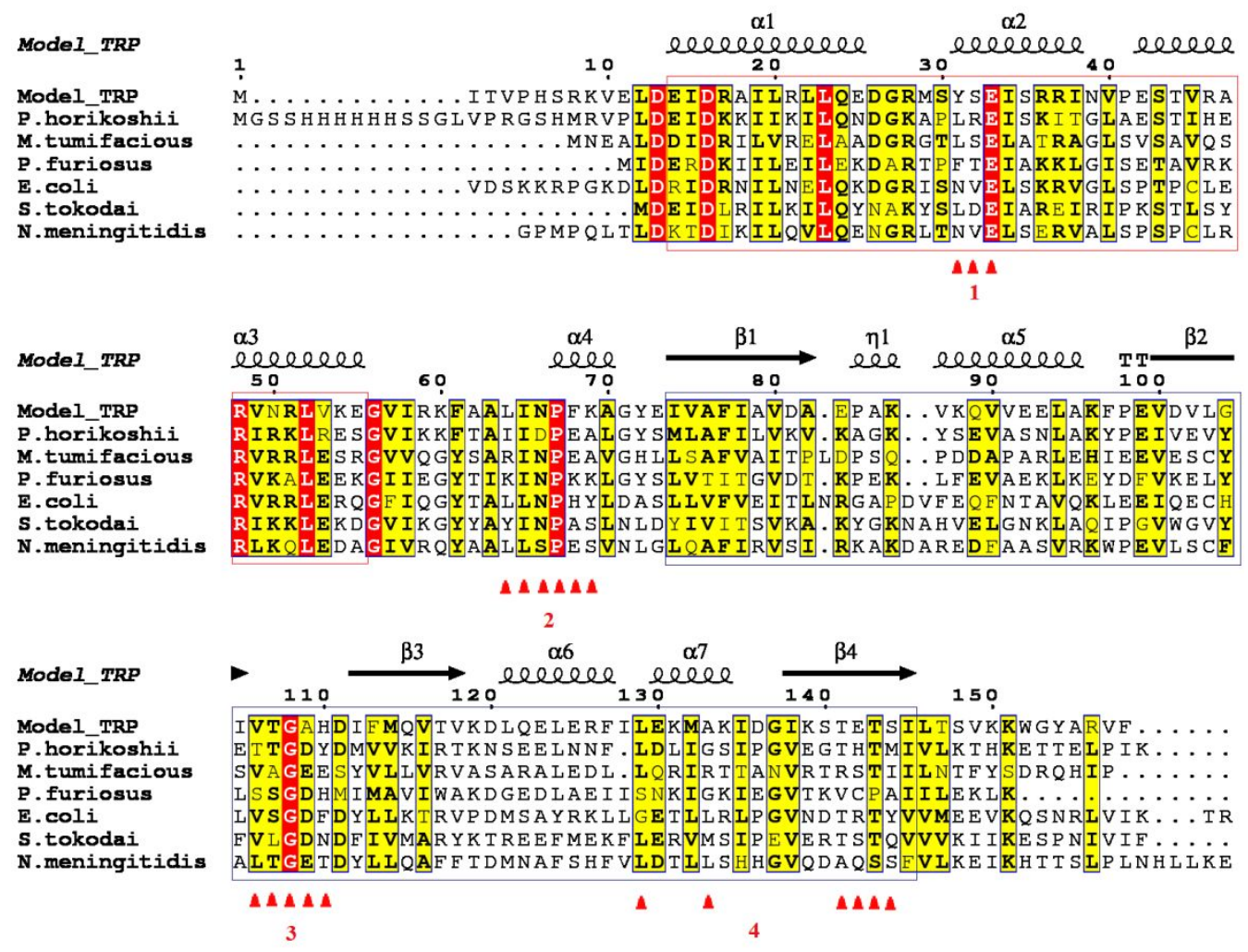

Figure S1. Sequence alignment of closely related Lrp proteins from other organisms using ClustalW. The structure based sequence alignment was performed using ESPript3v server. The active site residues are indicated in red color legends. The DBD is enclosed in light red box and EBD is enclosed in blue box. 


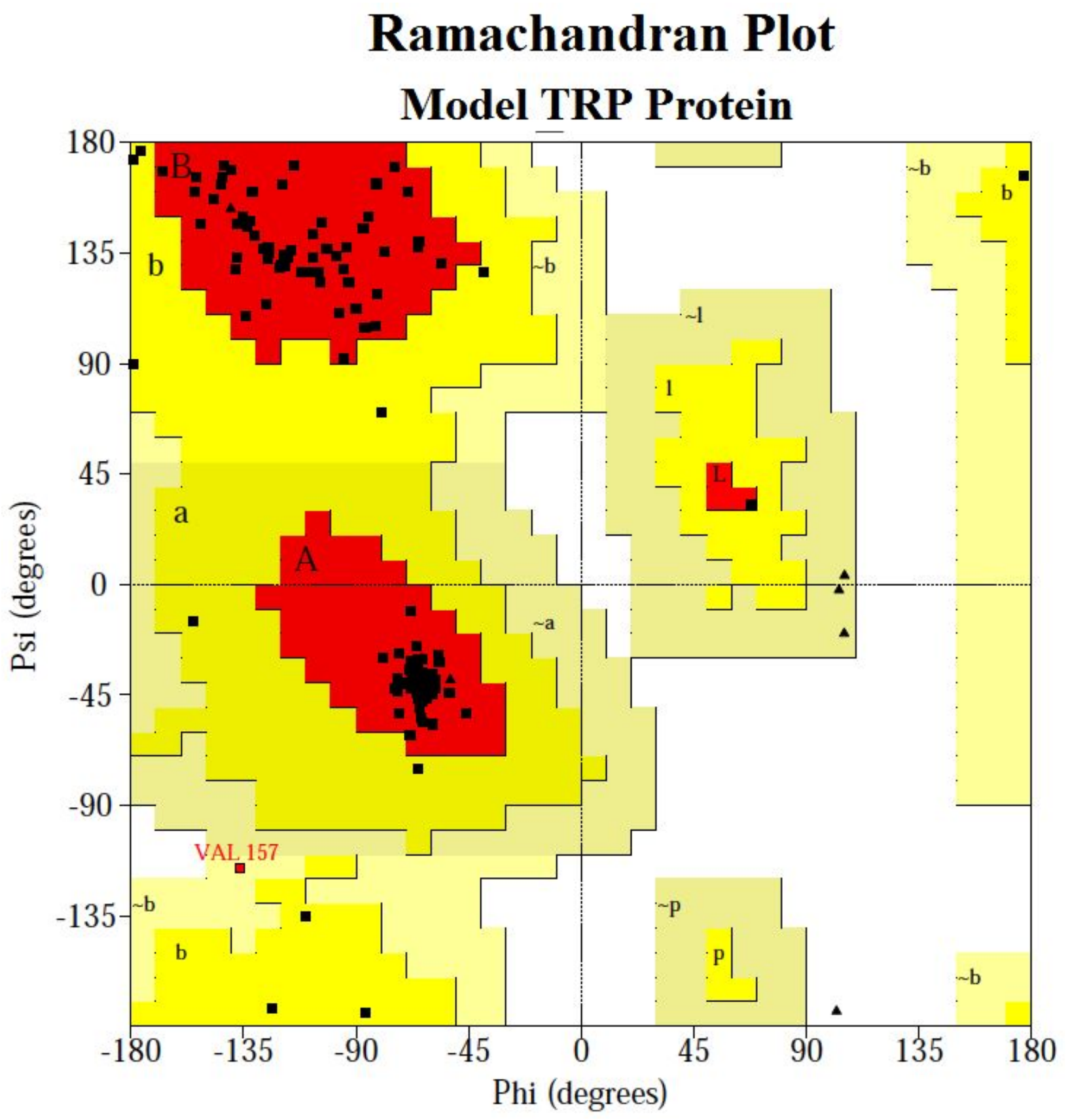

Figure S2. Structure validation of modelled TRP protein using SAVES server. All the residues are present in the allowed regions and Val157 residue only present in additionally allowed region. 


\section{RMSD}

Backbone after lsq fit to Backbone

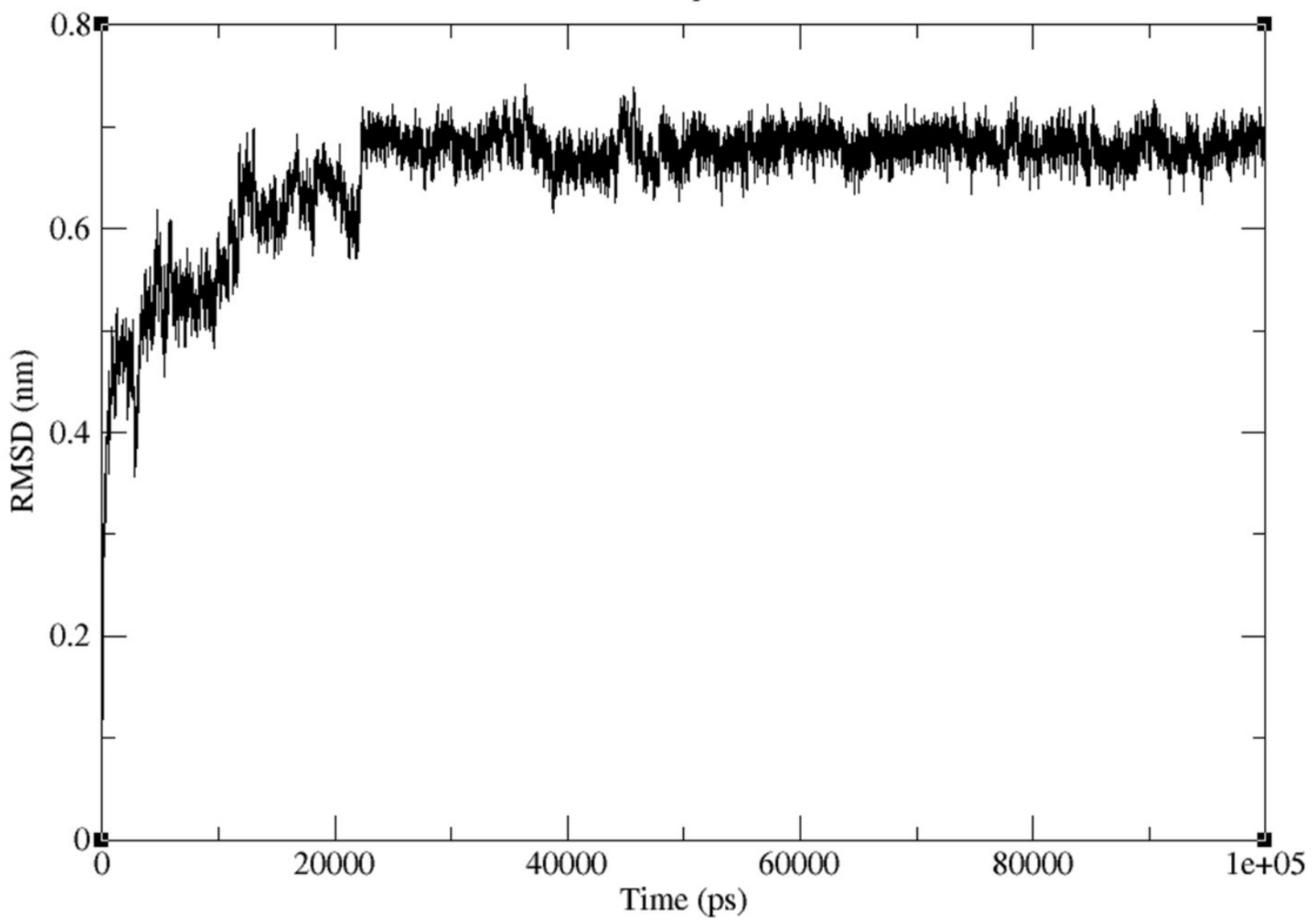

Figure S3. Backbone RMSD calculation representing the structural stability of modeled TRP protein. Structural deviation occurs within $22 \mathrm{~ns}$, from there on the stability of Protein sustained at $0.7 \mathrm{~nm}$ up to end of simulation. 


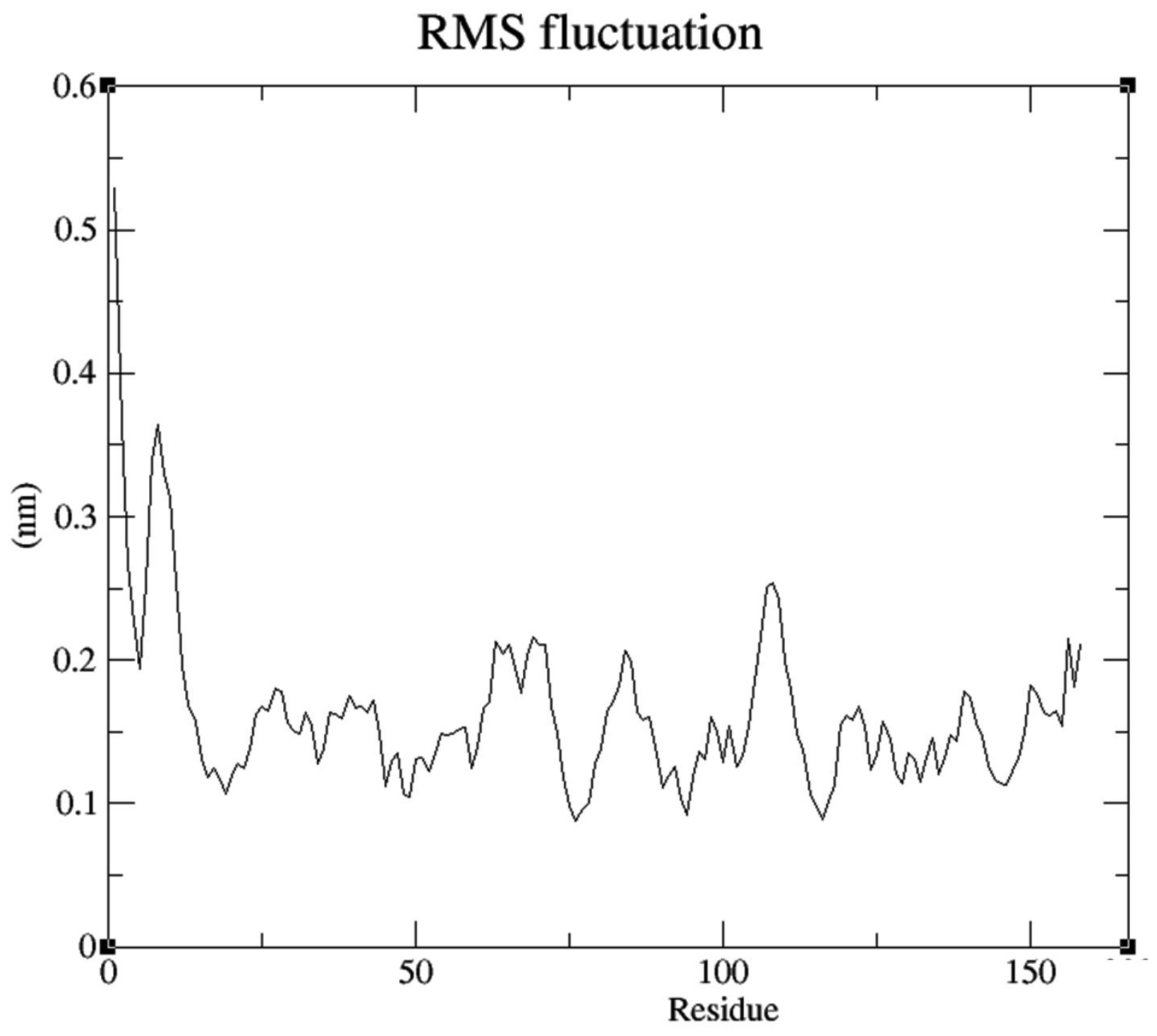

Figure S4. Computed residual RMSF of modeled TRP protein and the average fluctuation observed between 0.1 to $0.4 \mathrm{~nm}$ during $100 \mathrm{~ns}$ time period. 


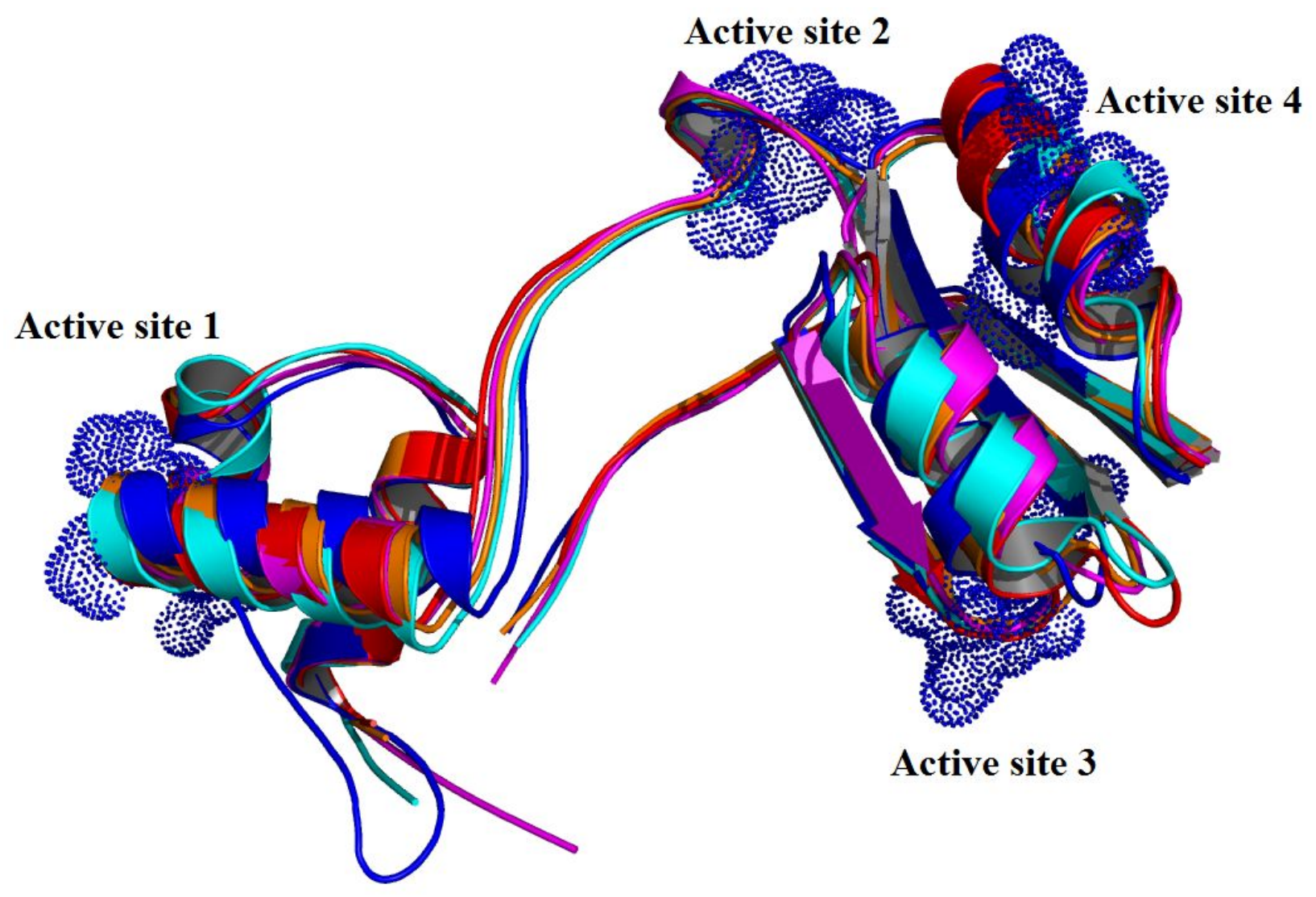

Figure S5. Structural superimposition of modeled TRP protein with Lrp like proteins (PDB IDs: 2EFP (red), 2CYY (pink), 2P6S (cyan), 2ZNZ (orange)) for active site pocket prediction. The four active site pockets of TRP protein is highly similar with experimentally reported structure which represented by dot view (blue color). 

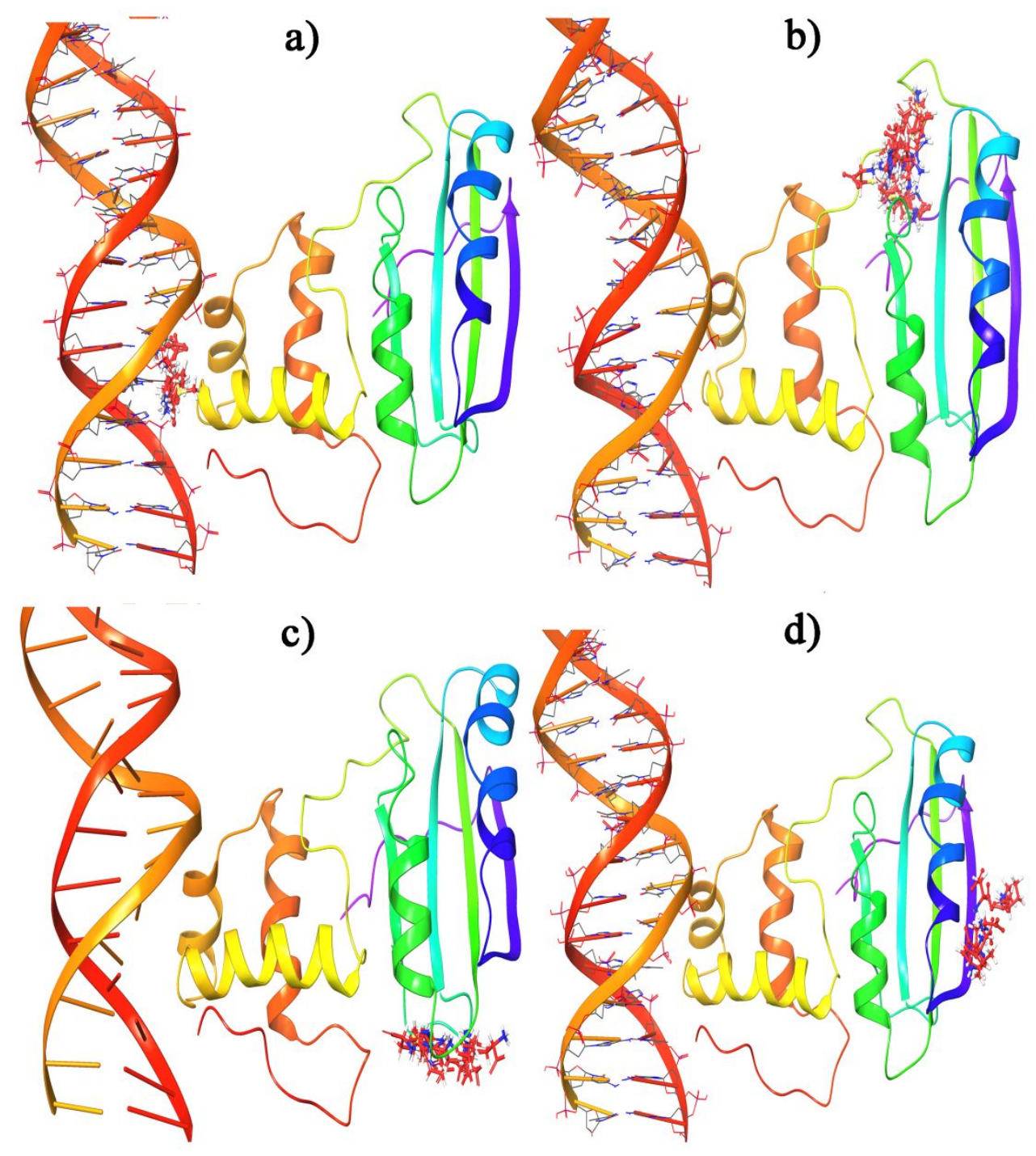

d)

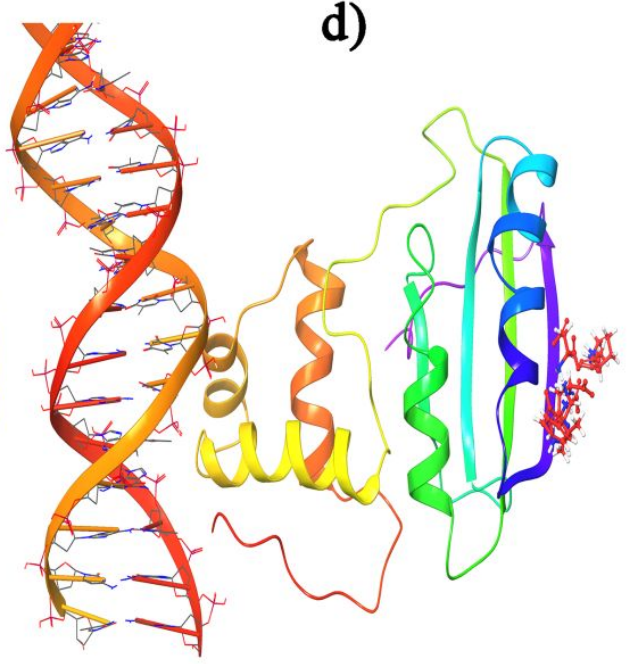

Figure S6. Binding of exogenous amino acids in alanine mutated four active site pockets of TRP protein (a) Act1 b) Act2 c) Act3 and d) Act4) 


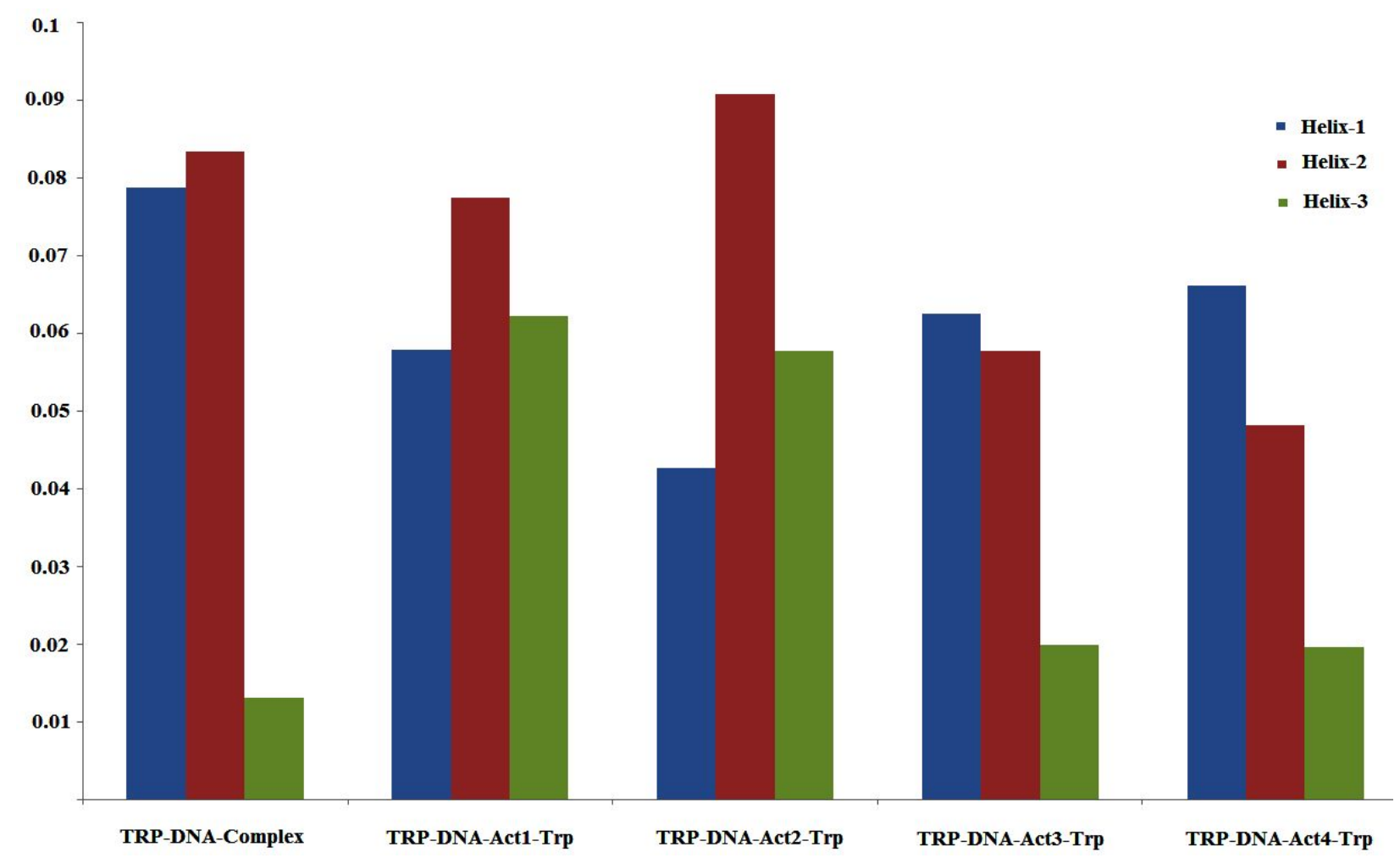

Figure S7. The average helical movement of TRP-DNA and TRP-DNA bound exogenous Trp amino acid complexes. The TRP-DNA, TRP-DNA-Act1-Trp and TRP-DNA-Act2-Trp complexes found to have high helical deviation compared with TRP-DNA-Act3-Trp and TRPDNA-Act4-Trp. The TRP-DNA-Act3-Trp and TRP-DNA-Act4-Trp complexes consist of similar helical deviation during $100 \mathrm{~ns}$ time period. 


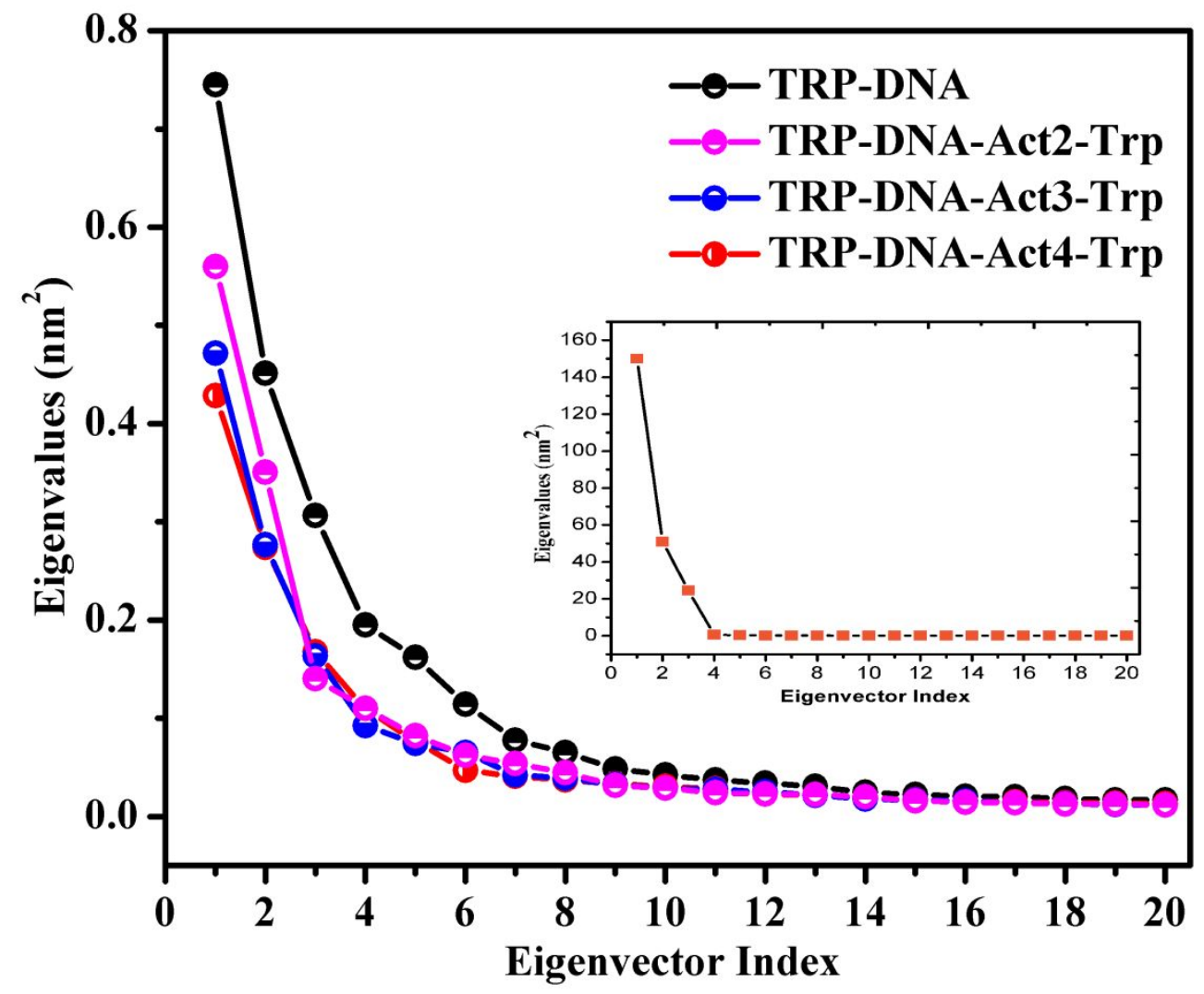

Figure S8. Eigenvalues and their corresponding eigenvectors (20 eigenvectors) obtained from the TRP-DNA (Black), TRP-DNA-Act-1-Trp (inset graph), TRP-DNA-Act2-Trp (Pink), TRP-DNA-Act3Trp (Blue) and TRP-DNA-Act4-Trp (Red) complexes simulations. 


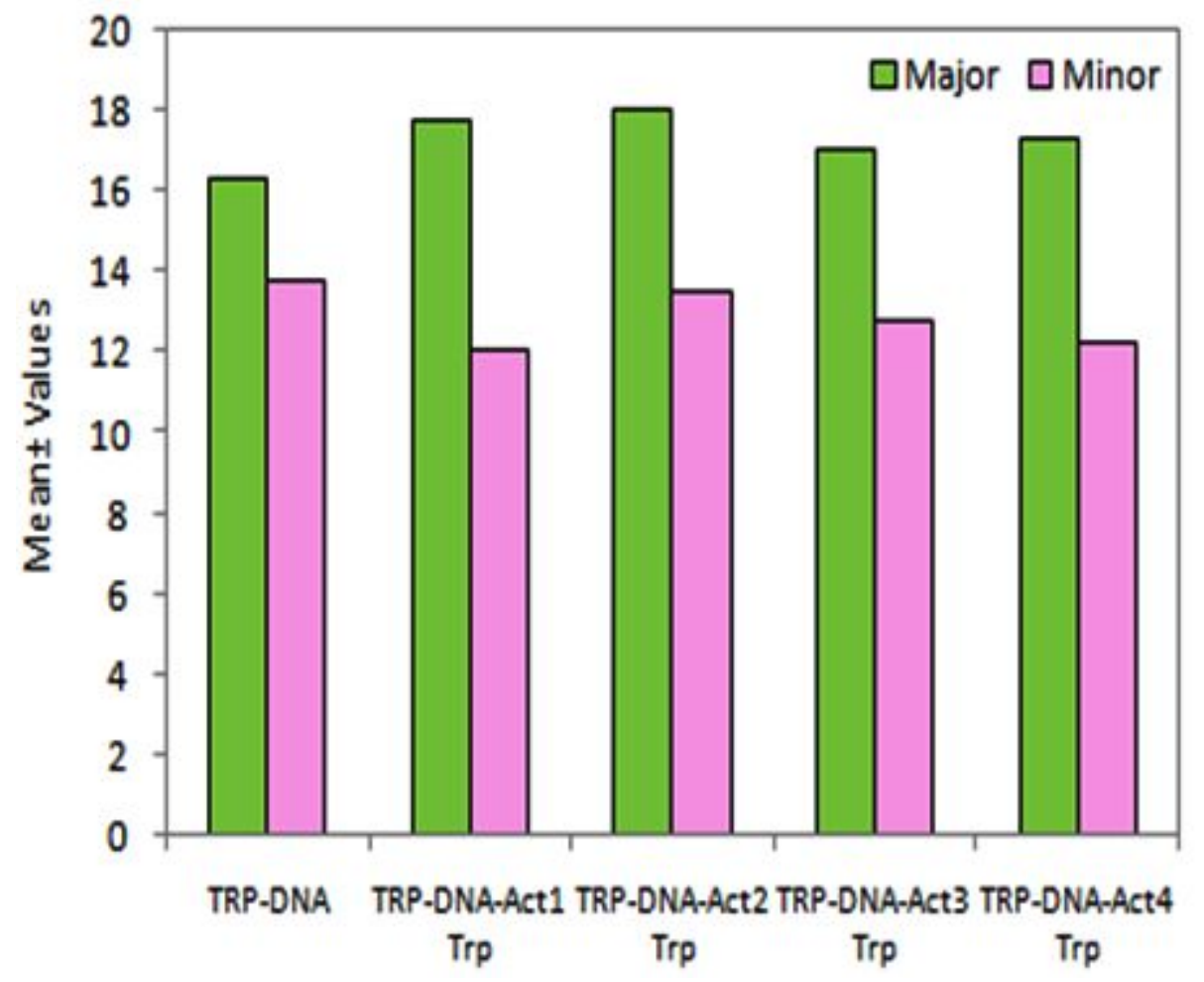

Figure S9. The major and minor groove mean deviation of DNA in different complexes induced by the protein and exogenous Trp amino acid. 
Table S1. Docking score of twenty exogenous amino acids in four active site pockets of TRP protein. Tryptophan amino acid binds predominantly in the all the binding pockets.

\begin{tabular}{|c|c|c|c|c|}
\hline \multirow{2}{*}{$\begin{array}{c}\text { Exogenous } \\
\text { amino acids }\end{array}$} & $\begin{array}{c}\text { Active site 1 } \\
\text { (Act 1) }\end{array}$ & $\begin{array}{c}\text { Active site 2 } \\
\text { (Act 2) }\end{array}$ & $\begin{array}{c}\text { Active site 3 } \\
\text { (Act 3) }\end{array}$ & $\begin{array}{c}\text { Active site 4 } \\
\text { (Act 4) }\end{array}$ \\
\cline { 2 - 5 } (kcal/mol) & $\begin{array}{c}\text { Docking Score } \\
\text { (kcal/mol) }\end{array}$ & $\begin{array}{c}\text { Docking Score } \\
\text { (kcal/mol) }\end{array}$ & $\begin{array}{c}\text { Docking Score } \\
\text { (kcal/mol) }\end{array}$ \\
\hline Tryptophan & $\mathbf{- 4 . 2 0}$ & $\mathbf{- 5 . 5 2}$ & $\mathbf{- 5 . 8 6}$ & $\mathbf{- 4 . 5 2}$ \\
\hline Aspartic acid & -3.83 & -3.80 & -4.06 & -3.21 \\
\hline Proline & -4.12 & -4.95 & -4.49 & -4.02 \\
\hline Histidine & -4.10 & -5.35 & -4.35 & -3.68 \\
\hline Phenylalanine & -4.04 & -3.82 & -4.32 & -4.43 \\
\hline Asparagine & -4.03 & -5.36 & -4.28 & -4.11 \\
\hline Valine & -3.78 & -5.23 & -4.26 & -4.12 \\
\hline Tyrosine & -3.71 & -3.84 & -4.05 & -4.00 \\
\hline Isoleucine & -3.53 & -4.51 & -3.27 & -3.45 \\
\hline Glutamic acid & -3.49 & -4.08 & -3.44 & -3.16 \\
\hline Glutamine & -3.41 & -4.60 & -4.21 & -3.55 \\
\hline Cystein & -3.37 & -4.61 & -4.43 & 3.19 \\
\hline Methionine & -3.20 & -3.59 & 3.22 & -3.18 \\
\hline & -3.19 & -4.31 & -3.99 & -3.59 \\
\hline & & & & \\
\hline
\end{tabular}




\begin{tabular}{|c|c|c|c|c|}
\hline Threonine & -3.11 & -4.91 & -4.18 & -3.59 \\
\hline Serine & -2.91 & -4.53 & -3.95 & -3.19 \\
\hline Lysine & -2.85 & -4.08 & -4.95 & -3.36 \\
\hline Arginine & -2.80 & -3.42 & -3.69 & -2.48 \\
\hline Alanine & -2.32 & -3.61 & -2.59 & -2.51 \\
\hline Glycine & -2.02 & -3.15 & -2.23 & -2.18 \\
\hline
\end{tabular}

Table S2. Docking score of twenty exogenous amino acids on four different active site pocket of Alanine mutated TRP-DNA complexes. The potential residues Ser43 in Act-1, Tyr72 in Act2, Gly108 in Act3 and Thr133 in Act-4 was mutated to Alanine residue.

\begin{tabular}{|c|c|c|c|c|}
\hline \multirow{2}{*}{$\begin{array}{c}\text { Exogenous } \\
\text { amino acids }\end{array}$} & $\begin{array}{c}\text { Active site 1 } \\
\text { (Act 1) }\end{array}$ & $\begin{array}{c}\text { Active site 2 } \\
\text { (Act 2) }\end{array}$ & $\begin{array}{c}\text { Active site 3 } \\
\text { (Act 3) }\end{array}$ & $\begin{array}{c}\text { Active site 4 } \\
\text { (Act 4) }\end{array}$ \\
\cline { 2 - 5 } & $\begin{array}{c}\text { Docking Score } \\
\text { (kcal/mol) }\end{array}$ & $\begin{array}{c}\text { Docking Score } \\
\text { (kcal/mol) }\end{array}$ & $\begin{array}{c}\text { Docking Score } \\
\text { (kcal/mol) }\end{array}$ & $\begin{array}{c}\text { Docking Score } \\
\text { (kcal/mol) }\end{array}$ \\
\hline Tryptophan & - & -3.11 & - & - \\
\hline Aspartic acid & -1.76 & - & - & -0.18 \\
\hline Proline & -3.38 & -2.37 & - & -2.17 \\
\hline Histidine & -4.19 & -3.99 & -2.72 & -1.83 \\
\hline Phenylalanine & - & -2.99 & - & -1.15 \\
\hline Asparagine & - & -3.58 & - & - \\
\hline Valine & -3.56 & -2.15 & - & -1.53 \\
\hline
\end{tabular}




\begin{tabular}{|c|c|c|c|c|}
\hline Tyrosine & $-\mathbf{5 . 1 1}$ & -2.73 & -3.59 & - \\
\hline Isoleucine & -3.44 & -2.02 & -1.65 & - \\
\hline Glutamic acid & -3.88 & -3.15 & - & - \\
\hline Glutamine & - & -3.40 & -3.18 & - \\
\hline Cystein & - & -3.20 & - & - \\
\hline Methionine & -3.19 & -2.27 & -1.54 & - \\
\hline Leucine & - & -2.51 & - & - \\
\hline Threonine & - & -2.34 & -4.71 & - \\
\hline Serine & - & -3.27 & -4.94 & - \\
\hline Lysine & - & -2.49 & -4.26 & - \\
\hline Arginine & - & -3.10 & -2.36 & - \\
\hline Alanine & -2.63 & -1.45 & -3.59 & - \\
\hline Glycine & -2.41 & -2.18 & - & \\
\hline
\end{tabular}


Table S3. The shortest allosteric communication network of Native TRP protein and TRP-DNA bound exogenous amino acid complexes. The residues highlighted in bold are potential active site pocket residues of the different complexes.

\begin{tabular}{|c|c|c|}
\hline & $\begin{array}{c}\text { TRP-DNA and bound } \\
\text { complexes }\end{array}$ & Communication Networks \\
\hline 1 & TRP Protein & B:L129-B:I128-B:M132-B:M114-B:I112-B:V90-B:I135 \\
\hline 2 & $\begin{array}{c}\text { TRP-DNA-Act-1-Trp } \\
\text { (S43) }\end{array}$ & B:S32-B:A46:B:V91-B:R59-B:V53-B:F61-B:I58-B:Y154-B:V106 \\
\hline 3 & $\begin{array}{c}\text { TRP-DNA-Act-2-Trp } \\
(\mathbf{Y 7 2})\end{array}$ & B:T72-B:E93-B:I135-B:I138- B:M132-B:L94-B:L103-B:R59- \\
\hline 4 & $\begin{array}{c}\text { TRP-DNA-Act-3-Trp } \\
\text { (G108) }\end{array}$ & B:G108-B:I112-B:V91-B:R59-B:V53-B:F61-B:M29-B:Y31 \\
\hline 5 & $\begin{array}{c}\text { TRP-DNA-Act-4-Trp } \\
\text { (T143) }\end{array}$ & B:T143 -B:V116-B:F113-B:V106-B:L103-B:F61-B:M29- B:I19- \\
& B:R48-B:B:I15-B:V40 \\
\hline
\end{tabular}

